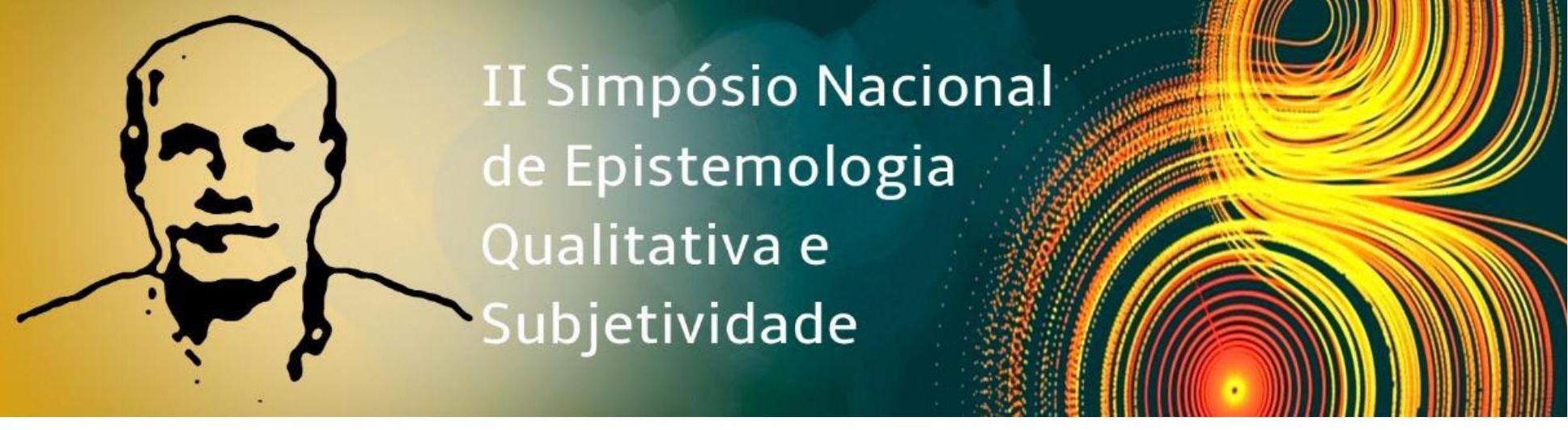

Eixo Temático: A subjetividade na formação de professores e outros profissionais

\title{
Constituição subjetiva da docência durante a implementação de uma horta escolar
}

Jeedir Rodrigues de Jesus Gomes, Secretaria Estadual de Educação do Pará, jeedirrod@gmail.com José Moysés Alves, Universidade Federal do Pará, jmalves@ufpa.br

\section{Resumo}

Objetivamos compreender como a experiência de implementação de uma horta escolar foi subjetivada por professores, contribuindo para sua formação continuada. Desenvolvemos a pesquisa em uma Escola Estadual de Ensino Fundamental e Médio, no Município de Belém do Pará, que aderiu ao regime de Educação Integral. Participaram da experiência 30 discentes e seis docentes. Durante todo o ano letivo de 2018, fizemos registros fotográficos, videográficos e por escrito de todas as atividades relacionadas à construção da horta. Também entrevistamos e registramos conversas informais com os participantes. Analisamos as oportunidades de aprender dos seis professores de ciências e interpretamos o modo como subjetivaram os diferentes momentos da implementação da horta (OLIVEIRA, 2016). O projeto de construção da horta foi motivado pela necessidade de melhorar o cardápio das refeições escolares. Além de possibilitar a educação alimentar e ambiental, a implementação da horta demandou conhecimentos de diferentes disciplinas. A resolução destes problemas exigiu ações inter e transdisciplinares, com perspectiva CTSA (CACHAPUZ, 2000). Professores e estudantes trabalharam de forma 


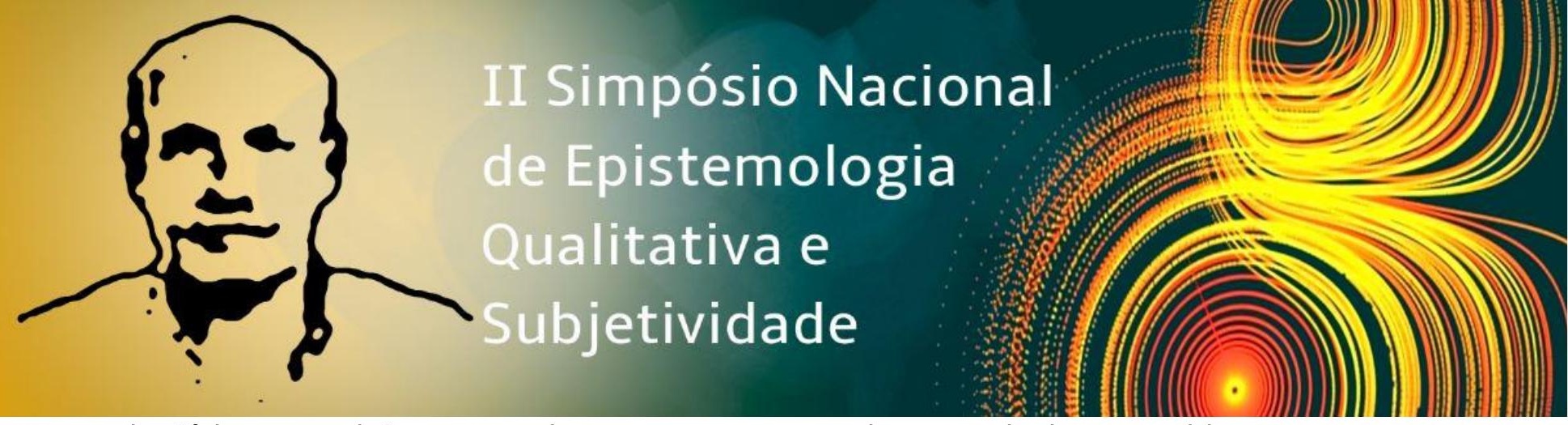

voluntária no projeto e se esforçaram para pesquisar e solucionar problemas que surgiram durante as ações realizadas, tais como o excesso de água no solo, o surgimento de fungos nas hortaliças e a desnutrição das cultivares. Durante o processo, os professores aprenderam sobre a importância da alimentação saudável, o prazer de trabalhar com a terra, como produzir adubo orgânico, como ampliar a produção, como semear de forma direta e indireta, a época adequada do plantio de cada espécie, o espaçamento e a profundidade entre as covas, a manutenção dos canteiros e o trato com as mudas em crescimento no laboratório. Apesar dos sentidos singulares da experiência para cada um, os professores entenderam o projeto como algo importante para a escola e para o próprio trabalho pedagógico. Também perceberam a experiência como oportunidade de formação continuada, que os valorizava enquanto sujeitos e profissionais. Investiram seu próprio esforço e conhecimentos para solucionar, criativamente (MITJÁNS MARTíNEZ; GONZÁLEZ REY, 2017), os problemas que surgiram. Também pensaram maneiras de utilizar pedagogicamente a horta. A oportunidade de observar o desempenho dos alunos em contexto diferente da sala de aula surpreendeu alguns professores. Em geral, o projeto gerou o sentimento de pertencimento, a integração de objetivos comuns, modificação na subjetividade dos professores, envolvimento e compromisso para além do aspecto intelectual dos sujeitos, pois se comprometeram emocionalmente com o projeto, aprendizagens foram expressas pela criatividade na solução de problemas e motivação durante o processo para estudar alternativas para resolver os problemas que surgiram. A pergunta que deixamos para o debate: como os professores são motivados a utilizar pedagogicamente a horta e aprender criativamente?

Palavras chave: Formação de Professores, Horta escolar, Teoria da subjetividade, Enfoque CTSA.

\section{Referências}




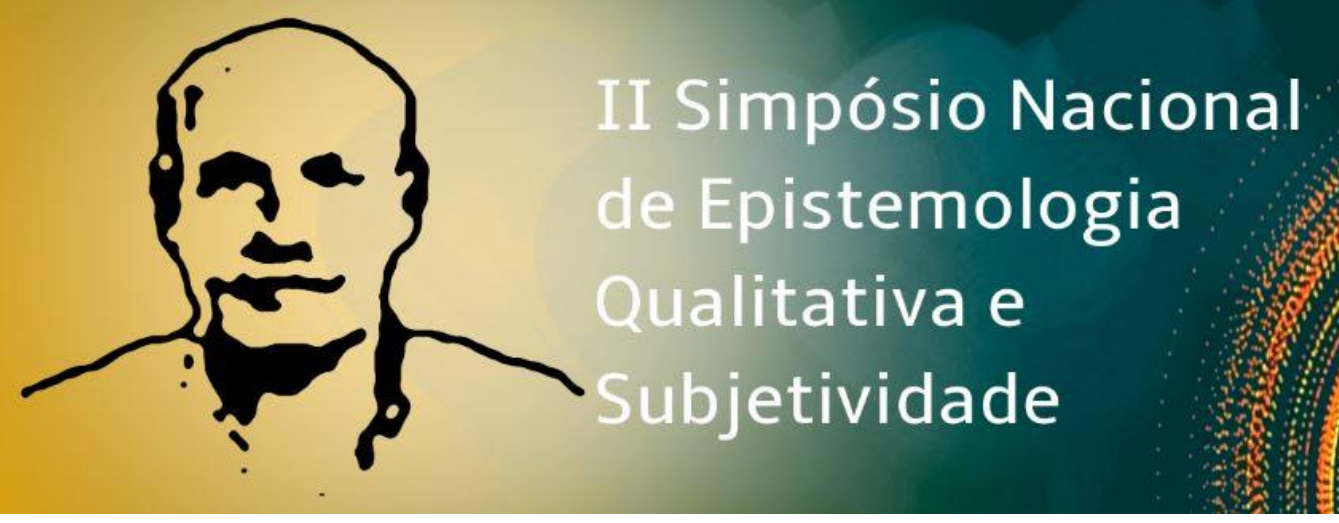

CACHAPUZ, A. F.; PRAIA, J. F.; JORGE, M. P. Perspectivas de ensino de ciências. Porto: Centro de Estudos em Ciência (CEEC), 2000.

MITJÁNS MARTíNEZ, Albertina; GONZÁLEZ REY, Fernando. Psicologia, educação e aprendizagem escolar: avançando na contribuição da leitura cultural histórica. São Paulo: Cortez, 2017.

OLIVEIRA, L. S. Constituição subjetiva de professores: caminhos alternativos para a formação continuada. Curitiba: CRV, 2016. 